\title{
Low Altitude/Large Scale Aerial Photographs: A Tool For Range And Resource Managers
}

\author{
MARK C. QUILTER AND VAL JO ANDERSON
}

$\mathrm{H}$ ow many times have you tried to explain or describe a site to someone, wishing you had a picture, knowing that the picture alone would describe the site? Low Altitude/ Large Scale (LA/LS) imagery can provide such pictures. Low Altitude/Large Scale imagery is simply an aerial photograph taken close to the ground, usually less than one thousand feet above ground level (Walker and De Vore 1995). These images can be obtained using a drone (a small remote controled airplane).

\section{The Drone}

The drone is able to take very detailed photographs because it flies close to the ground (50 to 1,000 feet) and slow (12 $\mathrm{mph}$ ). It is also small enough to be transported to a study area in a car or truck where it can be hand launched and then landed without a runway (see Figure 1. Drone). The drone can also

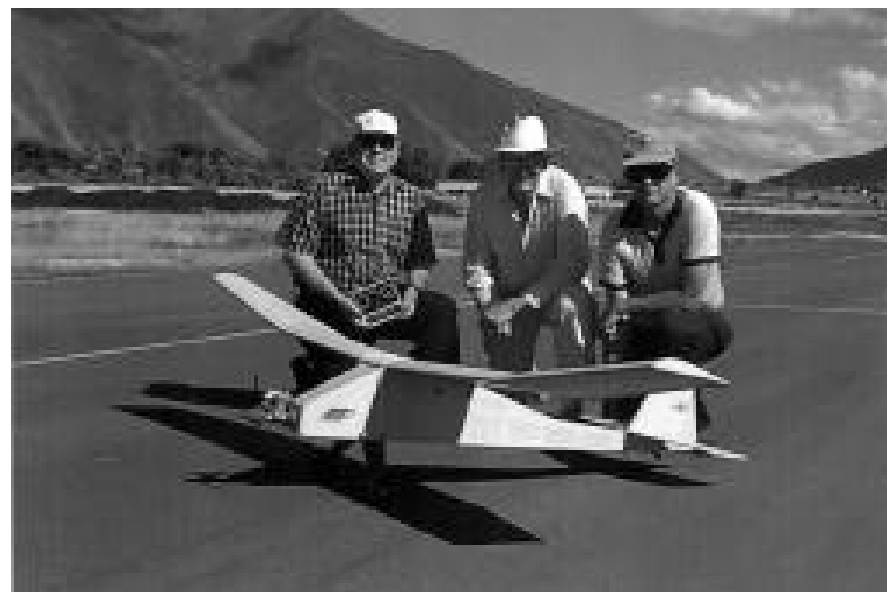

Fig. 1. Drone used for LA/LS photography with flight crew (left to right Wally Barrus, Dee Taylor, and Jim Walker).

be landed in very small areas; nets, or even "soft" trees have been used for landings. If necessary the craft can be launched at a distant location and then flown into a more remote site as the pilot either walks to the site or rides in the back of an open truck. A single image from the drone can cover up to 16 acres using a $28 \mathrm{~mm}$ lens to as small as a 24 by $36 \mathrm{ft}$. plot using a $50 \mathrm{~mm}$ lens. The drone is versatile because of its small size, simple control system, and ability to carry different camera systems. It can be quickly taken to almost any site without elaborate setup. The drones currently in use cost around one thousand dollars which includes engine, radios, $35 \mathrm{~mm}$ cam- era, and flight kits. Building the drone requires approximately one hundred plus hours depending on building skills (Walker and De Vore, 1995). Learning to fly the drone also requires practice. Even with the high labor costs in construction and flight training, using the drone is an economical method of obtaining aerial imagery of small areas. If highly detailed images are needed, the drone may be the only platform available.

\section{Cameras and Sensors}

The drone can carry several types of cameras. The photographs described in this report were taken using a $35 \mathrm{~mm}$ camera. We have used a color television camera which allowed us to see live and record, on a portable television / VCR what the drone was flying over. Digital cameras have been used along with the standard $35 \mathrm{~mm}$. However, the $35 \mathrm{~mm}$ camera provided the most detailed and reliable images compared to the video and digital cameras. We have also been able to have $35 \mathrm{~mm}$ film processed the same day as our flights using one hour photo processing stores. Even in remote areas of Idaho, Utah, and Wyoming, we have been able to find one hour film processing within a one to three hour drive from photographed areas. Our experience has shown that the quality of the $35 \mathrm{~mm}$ image is worth the delay in processing when compared to the image quality of the digital systems.

\section{Historical Documentation and Restoration Verification}

The Utah Department of Agriculture and Food has used this procedure to document stream and riparian restoration projects. Figures 2 and 3 are a set of photographs taken at 400 feet above a restoration project on Chalk Creek near Coalville, Utah. Figure 2 was taken during early spring to document the river's condition at low water while Figure 3 was taken in the late spring to catch the river at its flood stage. Figure 2 shows the construction of "barbs" (marked with arrows). A barb is a rock structure which redirects water into the center of a stream, thus protecting the bank from being eroded. These photographs not only document that the work has been done but shows that the barbs were placed and are functioning properly. As you look at the ripples formed by the water movement over the barbs you can see the water is redirected into the middle of the stream channel. This is demonstrated especially well in Figure 3 at flood stage (when most erosion would occur). Notice how the ripples formed by the barbs are directed to the center of the stream (arrows mark the ripples). This aerial perspective gives an overview of the whole site 


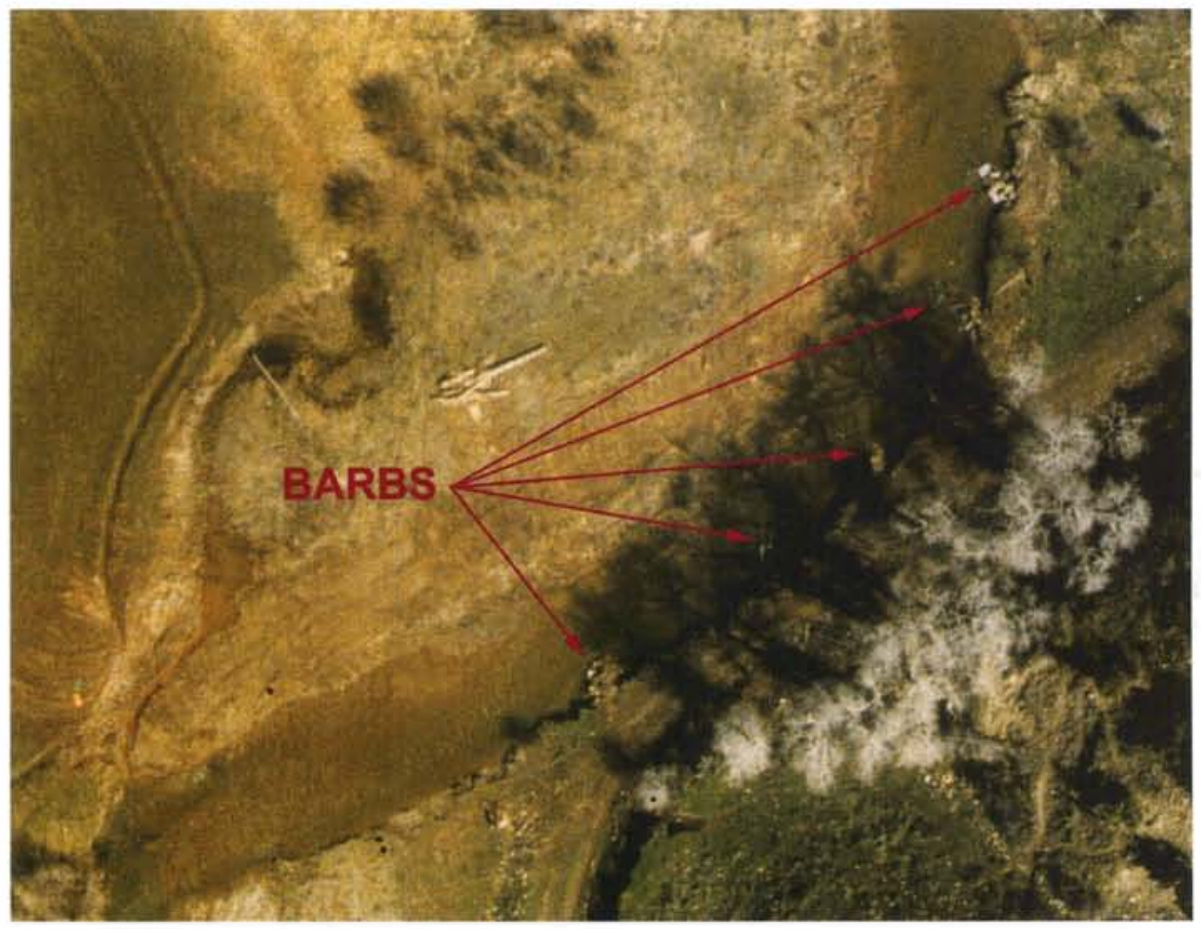

Fig. 2. Riparian restoration site near Coalville, Utah at "low flow".

showing the relationships of all elements of the scene.

Not only do the photographs document the barb construction but details like fencing (labeled with the letter A in Figure 3) can be seen in the image. Notice the lower left area of Figure 3,

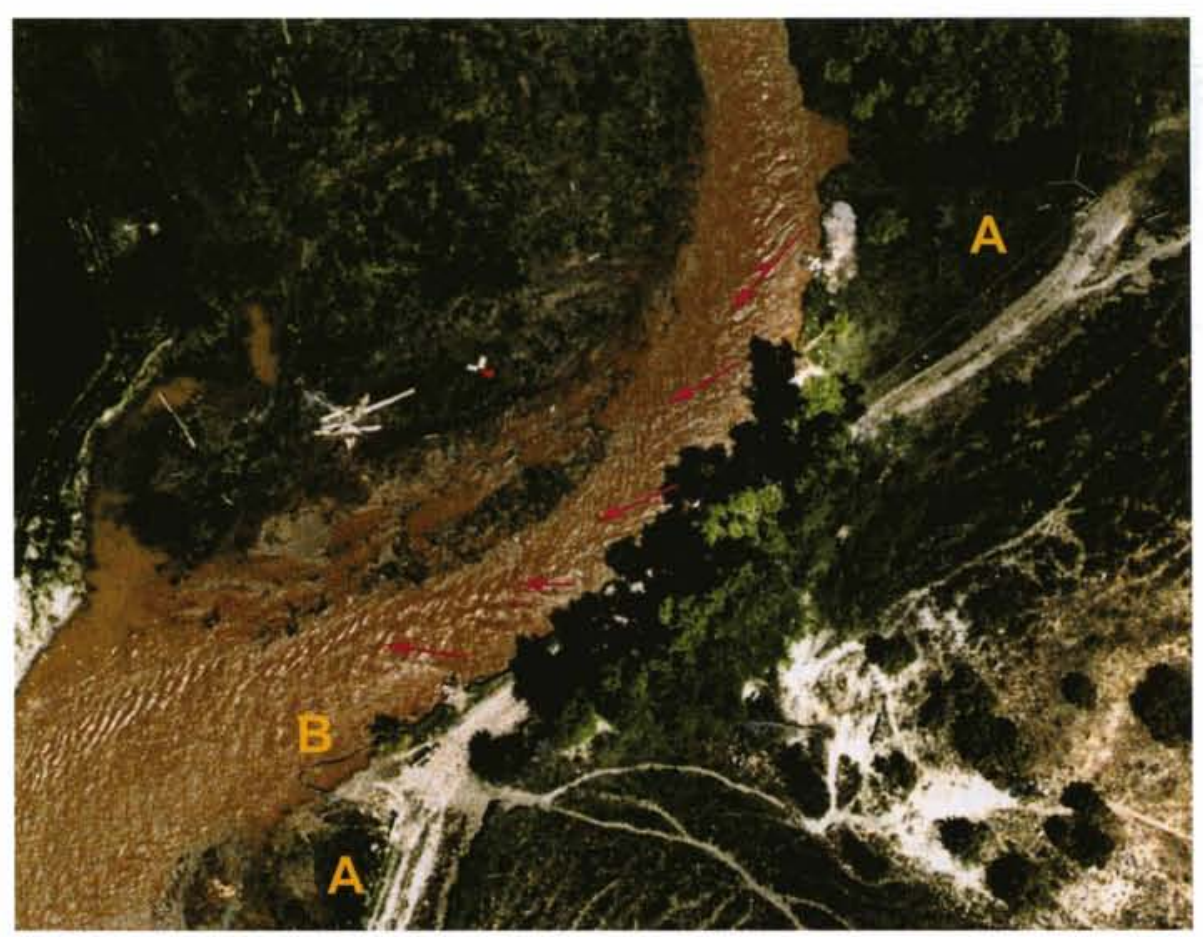

Fig. 3. Riparian restoration site near Coalville, Utah during spring runoff. completed work and evidence that the projects are functioning properly. It should be noted that these two images are a subset of photographs which cover the entire section of the river.

\section{Sampling Hard to Reach Areas}

Another use of the LA/LS imagery is to get information from places which are hard or impossible to access manually (see Figure 4 Shoshone Falls). Figure 5 is an aerial picture of islands formed by Shoshone Falls near Twin Falls, Idaho. This image was photographed about 300 feet above the top of the concrete wall marked as point $\mathrm{A}$. The base of the granite rock marked $\mathrm{B}$ is about seventy five feet below the point $\mathrm{A}$. By using overlapping photographs and a stereo scope it is possible to see the image in three dimensions. Stereo viewing of this image made it possible to identify the 155 dots labeled as " $\mathrm{C}$ " on the rocks in Figure 5. These dots appeared on other images taken of the cascading water (not shown) and were puzzling. In stereo they could be clearly identified as birds flying in the mist of the waterfall at different heights. It was also noted that the dots on the rocks changed places in sequential images showing that they were not attached to the rocks. Not only can the birds be seen but also the different types of vegetation and their location can be seen. By using the photographs these isolated areas can be sampled without personnel being exposed to the extremely difficult and hazardous rocky cliff islands.

\section{Non-Destructive Vegetation Sampling}

Some sites may be easy to access but they are fragile and can be damaged or disturbed by standard sampling procedures. At times disturbances such as ORV use need to be documented without disturbing the site more. The drone is an excellent tool for doing non-destructive, non-obtrusive sampling because it flies over an area without making contact. For example, Figure 6 is a Dwarf bear claw poppy/cryptogamic crust community near St. George, Utah that has been disturbed by ORV's. These crusts are very sensitive to sur- 


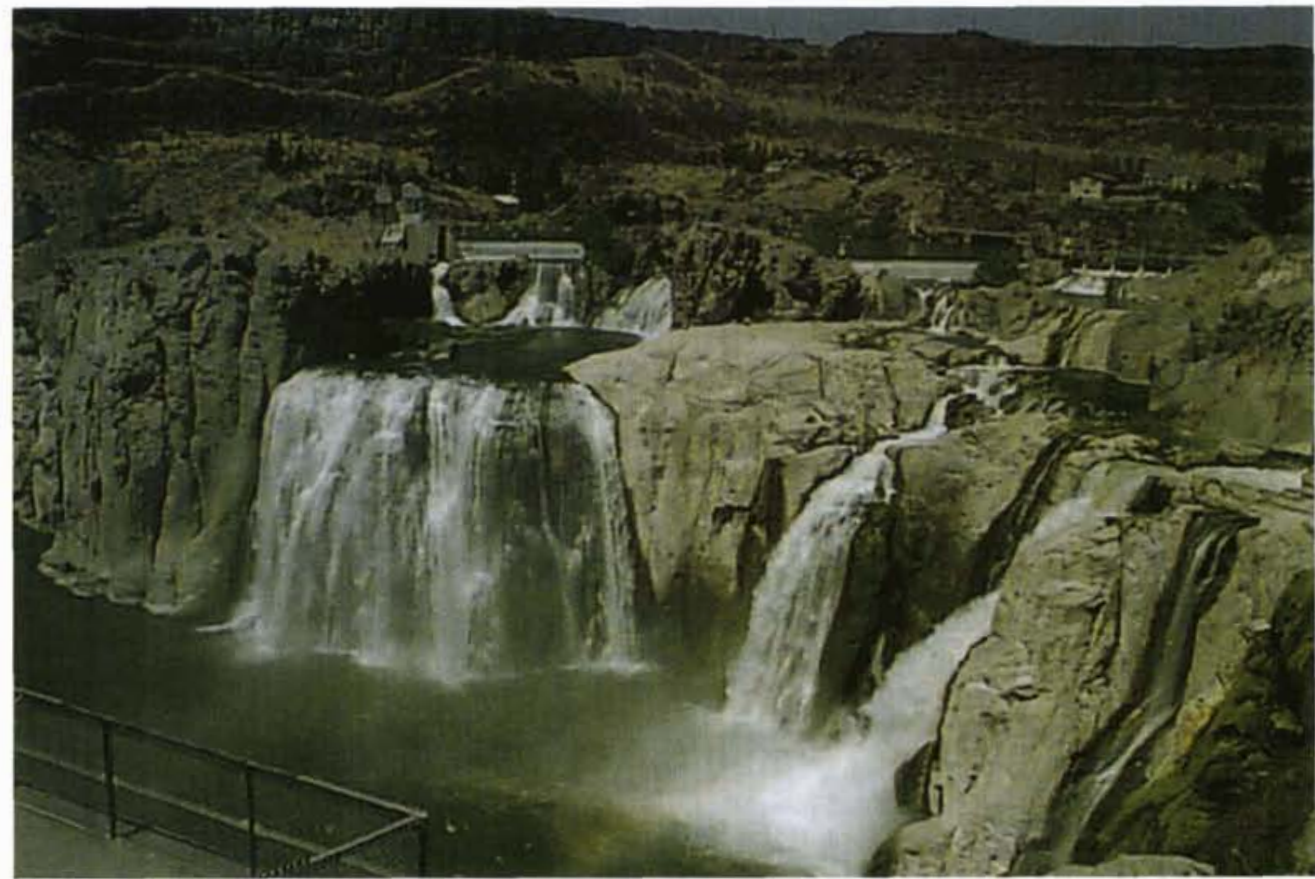

Fig. 4. Shoshone Falls near Twin Falls, Idaho photographed from the ground.

face traffic of any kind as shown by the damage of the ORV tracks. By flying over the site and recording it on film, critical measurements can be made on the film without disturbing the site. With the use of targets (marked $\mathrm{E}$ on Figure 6) and knowledge of photogrammetry many measurements can be made such as size, height, and area of objects in the image including the extent of ORV damage. From this mosaic photograph, measurements such as the areas of crusts (dark brown areas marked A), ORV erosion (light linear areas marked B), individual bear claw poppy plants (light circular shapes marked C), soil type (red and white shades), and gopher disturbance (light circular patches marked D) can be measured. Population counts of the poppies can be made as well as individual plant parameters such as width and height, from measuring the images of plants and their shadows. Population transects can also be made using the photographs with out trampling the fragile crust area or stepping on plants.

\section{Multiple-Attribute Data Collection From a Single Survey}

Low Altitude/Large Scale photographs can be used to document an instant in history similar to standard photo plot techniques. At the time of exposure the scene is frozen. Successive flights can be used to measure change in all aspects of the photographed site by comparing a series of photographs. These photos are unique from standard ground based photo plots because they give an aerial perspective of a plot as well as the surrounding area. Because the LA/LS images are vertical and highly detailed, transects can be marked on photographs and measurements made expanding their utility as a photo plot. For example, imagery may have been taken to look at a single species population distribution. In later images it may be seen that ORV use has expanded. It is possible with the LA/LS imagery to go back to previous images and measure ORV disturbance and compare measurements obtained from current images.

The photographs record everything that is present. Therefore, if new information is needed that was not collected in the field, the image can be used without revisiting the site. This saves on

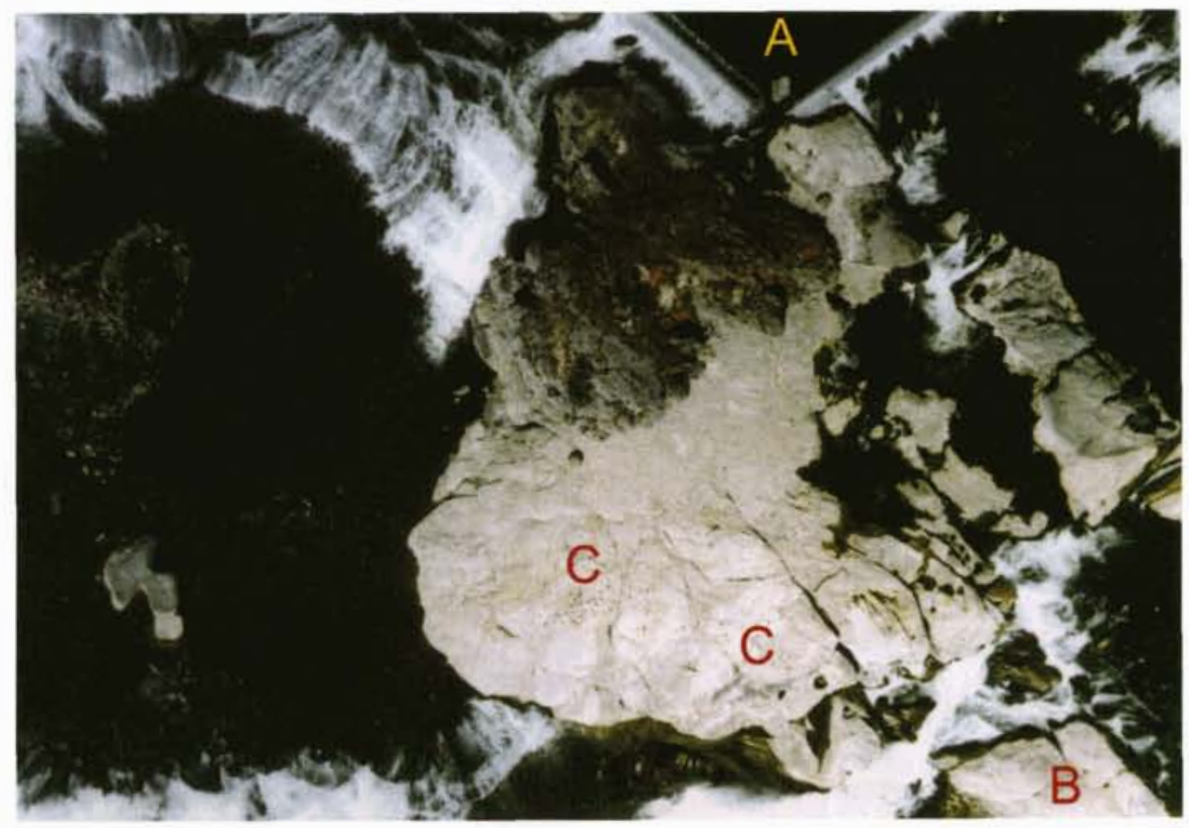

Fig. 5. Islands formed by Shoshone Falls. Photograph taken from 300 feet above the falls. 


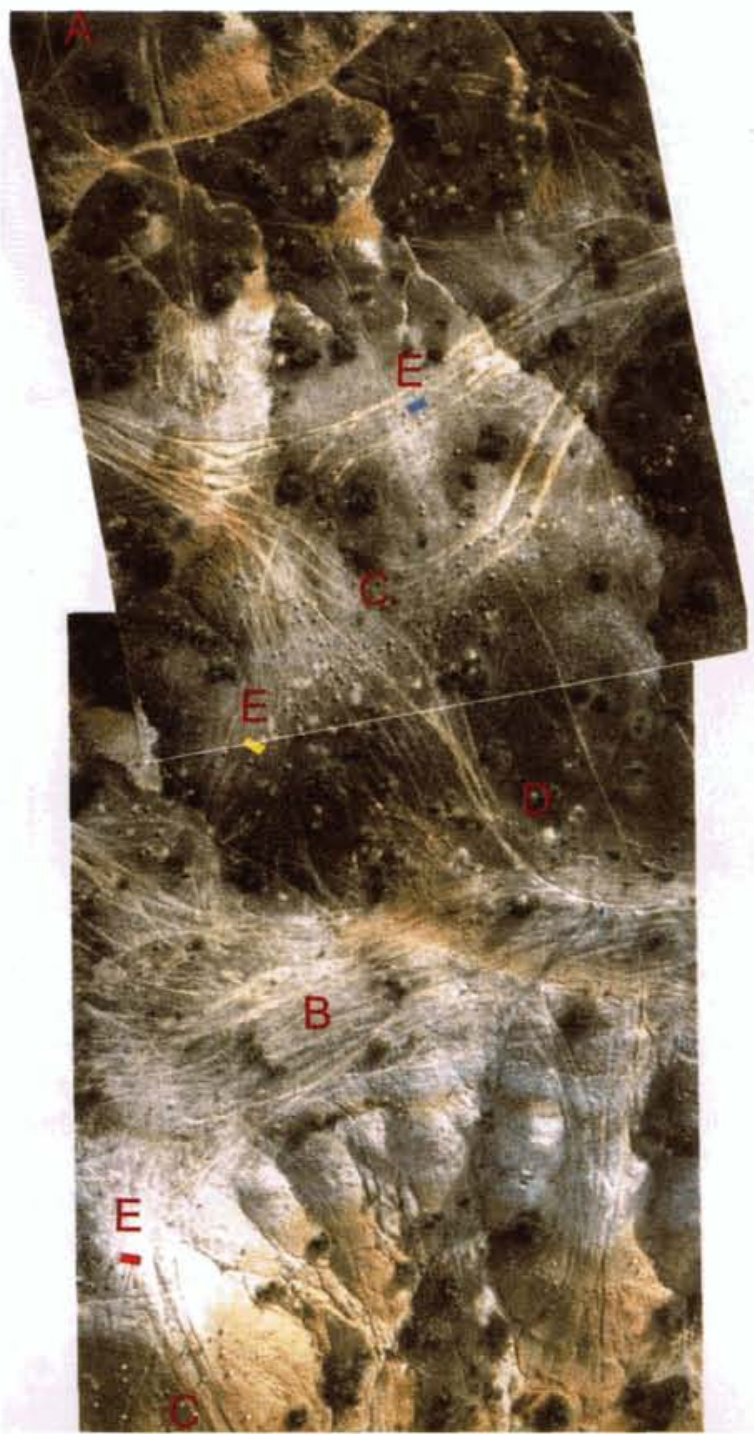

The measurements are also made with smaller equipment reducing the cost of labor.

\section{Infra-Red Film as a LA/LS Tool}

The most popular film size is the $35 \mathrm{~mm}$ format, which comes in a large assortment of film types and speeds. Figure 7 is a photograph taken near Morgan, Utah using Kodak's new E-6 process infra-red (IR) film. Since this film is developed using the standard E-6 processing IR images can be viewed the same day they are taken. This is important for range management when one needs to know plant health as related to drought stress or insect and disease damage within a short period of time. In the IR film, healthy vegetation is a bright magenta color with unhealthy or sparse vegetation appearing dark green or yellow. This type of image is ideal for studying vegetation health and cover. For example, on
Fig. 7 at the area labeled A, tire tracks from a fertilizer spreader can be seen. Here the tires have crushed the alfalfa damaging the stems of plants and reducing the IR reflectance causing tire marks to be lighter in color than the healthy uninjured plants.

This image was flown in the spring and shows the new budding willows (B) compared to the faster growing alfalfa (C) which appears magenta-red. Also moist soils of the sides of the brook are darker (D) than drier soils (E) of the eroded hillside. Feeding areas (F) are also visible as white-yellow blotches caused by the yellow straw left from the trampled hay. Though the color is the same as dry soil, the feeding area can be identified by the circular patterns with blotches where hay bales were deposited.

After studying this image for awhile, you should be able to identify the downy brome grass amongst the sage brush $(\mathrm{G})$ (it is growing rapidly and so will have a bright magenta color), the riparian zone and stream, cattle grazing $(\mathrm{H})$, and fence lines (I). This type of image is an excellent tool in resource management not only because it gives a detailed map-like view of a range site, but, it allows our eyes to visualize the health of the vegetation and soil condition.
Fig. 6. Dwarf Bear Claw Poppy site near St. George, Utah.

labor and work that would be required using traditional transect or quadrat sampling. Photographs record all that is visible as a two dimensional picture. Transects are singular in dimension. Photographs then can be used to sample large areas with quadrats being either the entire image or smaller quadrats marked off on the image. An advantage of the drone is that photographs cover much more area than traditional sampling methods and record all the information for the entire site in just moments. The labor intensive measurements can then be done in the comfort of an office and without the pressure of costs associated with time in the field.

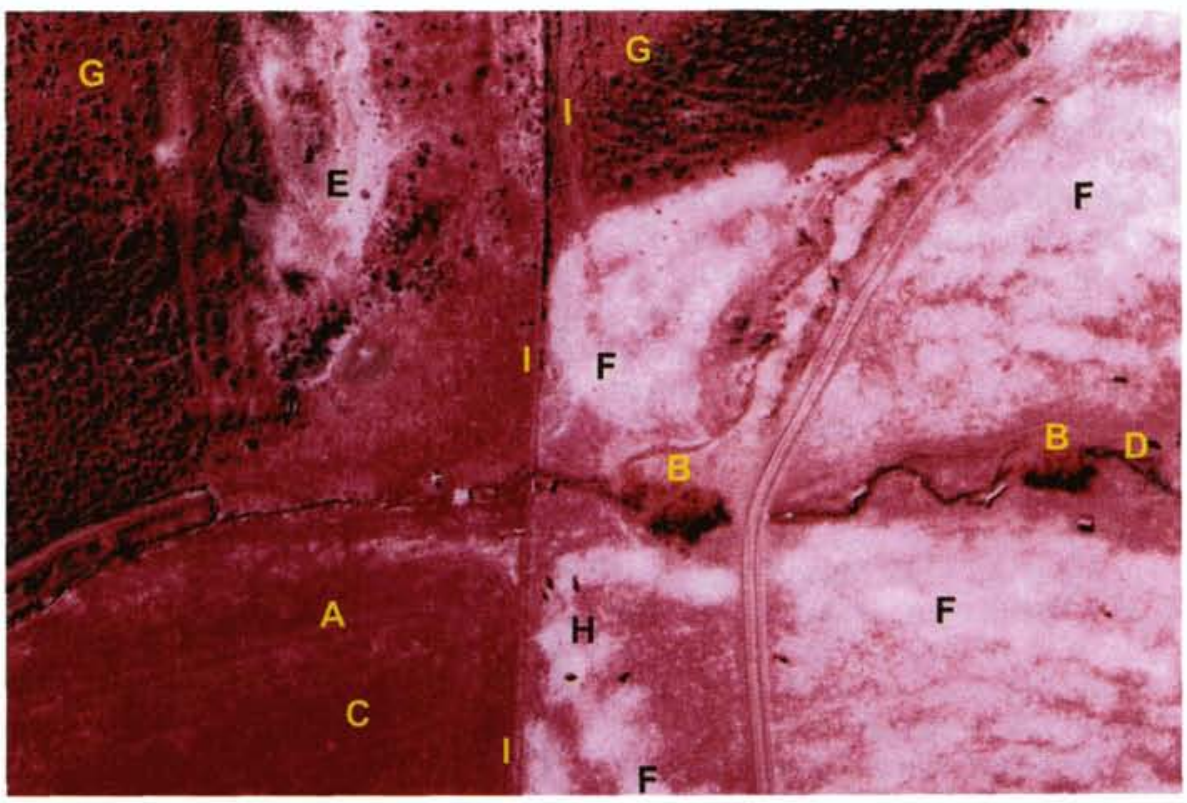

Fig. 7. Infra-red photograph of pasture and range site near Morgan, Utah. 


\section{Conclusions}

As demonstrated by the images presented, LA/LS imagery can give land managers a new perspective of their resource. This technology is simple to use, economical, and timely in producing aerial photographs of small areas.

The use of a $35 \mathrm{~mm}$ camera gives the manager a wide selection of films and quick processing times. The images in this report were acquired using KODAK GOLD 200 print and Kodak Ektachrome Infrared (EIR) slide films. Both of these films can be processed the same day the film is used.

One of the most beneficial uses of the drone is to record and document a site at a given time. Once the photograph is taken it is a permanent record. It can be used to compare to later images to observe change. Not only can change be detected but the image can be used for other studies not planned in the original flight. This was demonstrated with the Shoshone Falls images which were originally used to map vegetation but also provided population counts of swallows. With such a drone and camera, a land manager can have a birds eye view of his stewardship. Pictures can document, provide information, and can be shared with others to help them better understand the resources and the management practices used on them in a very economical way.

\section{Cited References}

Quilter, Mark C. 1997. Vegetation Monitoring Using Low Altitude, Large Scale Imagery From Radio Controlled Drones. Dissertation, Botany and Range Science Department, Brigham Young University, Provo, Utah.

Walker, James and Steven L. De Lore. 1995. Low Altitude Large Scale Reconnaissance: A Method of Obtaining High Resolution Vertical Photographs for Small Areas. Interagency Archeological Services, Division of Partnerships and Outreach, Rocky Mountain Regional Office, National Park Service, Denver, Colorado.

Authors are: Environmental Practices Specialist, State of Utah Department of Agriculture and Food, PO Box 14600, Salt Lake City, Utah 84114-6500; and Professor, Botany and Range Science Department, Brigham Young University, Provo, Utah 84602

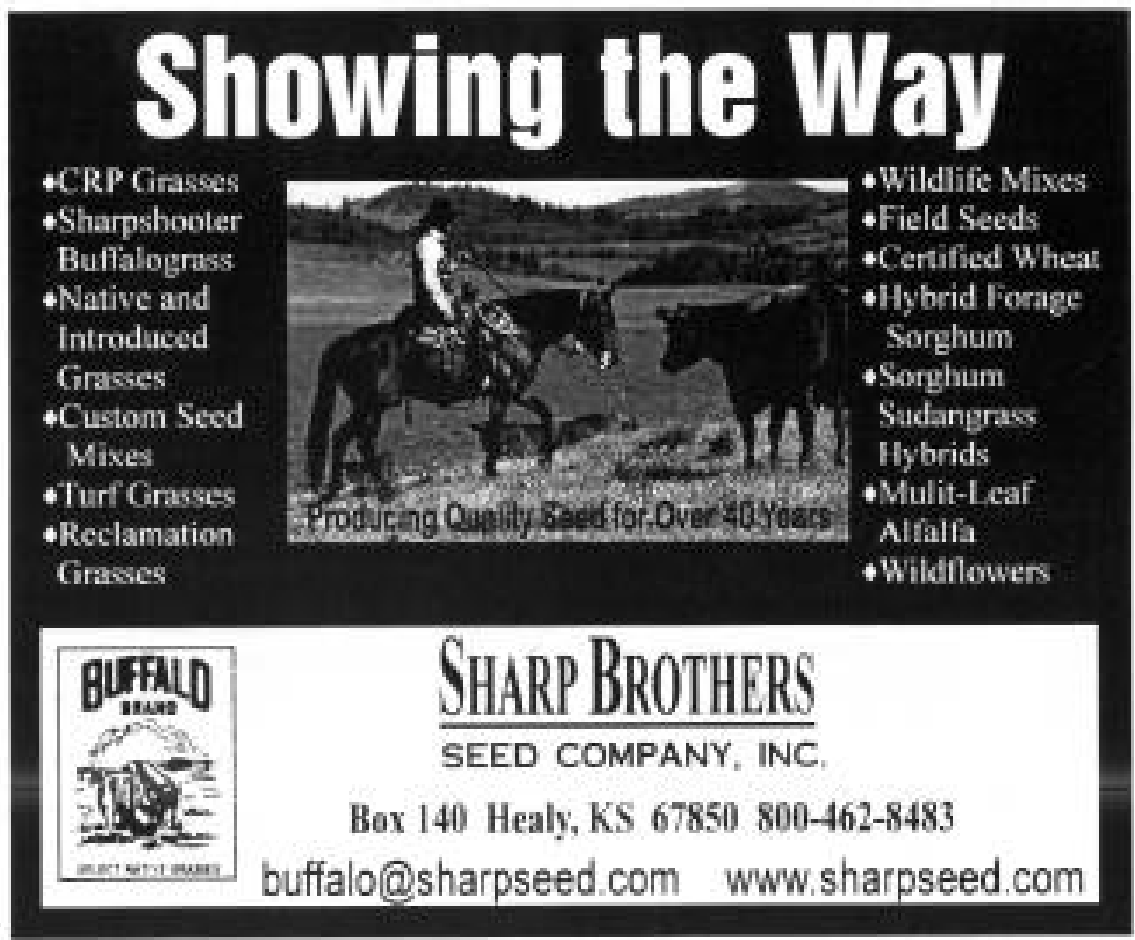

